\title{
Experiências narradas por homens no exercício da paternidade: rompendo paradigmas
}

Experiences narrated by men in the exercise of fatherhood: breaking paradigms

Experiencias narradas por hombres en el ejercicio de la paternidad: rompiendo paradigmas

\section{Glaucia Resta Dal-Rosso', Silvana de Oliveira Silva II, Greice Machado Pieszak ${ }^{I I I}$, Sandra Beatris Diniz Ebling ${ }^{\mathrm{IV}}$, Vanessa do Nascimento Silveirav}

Resumo: Objetivo: conhecer as experiências vivenciadas por homens no exercício da paternidade. Método: estudo qualitativo descritivo-exploratório, realizado com 15 homens que acompanharam suas parceiras em um curso de gestantes. A produção de dados ocorreu por meio de entrevista narrativa e utilizou-se a análise de conteúdo temática. Resultados: os homens deste estudo vivenciaram a paternidade ativamente, auxiliando no cuidado com os filhos em relação à manutenção das necessidades básicas e da educação. As vivências geraram impactos pessoais como o interesse no cuidado de si e a busca por informações para qualificar o exercício da paternidade. Considerações finais: a enfermagem pode contribuir para o fortalecimento do exercício da paternidade por meio de ações que valorizem o cuidado e a inserção dos homens no sistema de saúde

Descritores: Saúde do homem; Paternidade; Enfermagem

Abstract: Aim: to know the experiences of men in the exercise of paternity. Method: a descriptive-exploratory study with a qualitative approach, conducted with 15 men who accompanied their partners in a course for pregnant

\footnotetext{
${ }^{\text {I }}$ Nurse. Universidade Integrada do Alto Uruguai e das Missões - URI. Santiago, Rio Grande do Sul (RS), Brazil. E-mail: glauciaresta@gmail.com. ORCID: 0000-0002-2532-420X

II Nurse. PhD student in Nursing Post-Graduation Program in Nursing, Universidade Federal de Santa Maria. Nursing Course Teacher, Universidade Integrada do Alto Uruguai e das Missões - URI. Santiago, RS, Brasil. E-mail: enfsilvanaoliveira@gmail.com. ORCID: 0000-00021016-0062

III Nurse. PhD student in Post-Graduation Program, Universidade Federal do Rio Grande. Nursing Course Teacher, Universidade Integrada do Alto Uruguai e das Missões - URI. Santiago, RS, Brazil. E-mail: greicepieszak@gmail.com. ORCID: 0000-0003-4980-3253

${ }^{\text {IV }}$ Nurse. PhD student in Nursing Post-Graduation Program, Universidade Federal do Rio Grande. Teacher, Universidade Federal do Pampa. Uruguaiana, RS, Brazil. E-mail: sandrabebling@gmail.com. ORCID: 0000-0002-0876-5206

v Nurse. Masters student of Graduate Program in Nursing, Universidade Federal de Santa Maria. Santa Maria, RS, Brazil. E-mail: vanessa.sylveira@hotmail.com. ORCID: 0000-0001-6289-8977.
} 
women. The production of data occurred through a narrative interview and the analysis of thematic content. Results: the men in this study experienced paternity actively, helping to care for their children in relation to

maintaining basic needs and education. The experiences generated personal impacts such as interest in self care and the search for information to qualify the exercise off paternity. Final considerations: nursing can contribute to strengthening the exercise of paternity through actions that value the care and insertion of men in the health system

Descriptors: Men's Health; Paternity; Nursing

Resumen: Aim: to know the experiences of men in the exercise of paternity. Method: a descriptive-exploratory study with a qualitative approach, conducted with 15 men who accompanied their partners in a course for pregnant women. The production of data occurred through a narrative interview and the analysis of thematic content. Results: the men in this study experienced paternity actively, helping to care for their children in relation to maintaining basic needs and education. The experiences generated personal impacts such as interest in self care and the search for information to qualify the exercise off paternity. Final

considerations: nursing can contribute to strengthening the exercise of paternity through actions that value the care and insertion of men in the health system.

Descriptores: Salud del Hombre; Paternidad; Enfermería.

\section{Introdução}

Nas últimas décadas, o papel paterno passou por diversas transformações, ultrapassando a perspectiva de único provedor financeiro do lar e passando a participar de forma mais ativa na vida dos filhos. Essa constatação fez com que as investigações científicas, em especial a partir da década de 70, se voltassem para o tema. ${ }^{1}$ Desse modo, pode-se afirmar que, atualmente, a concepção de paternidade está em processo de construção e reconstrução em virtude das transformações advindas dos novos conceitos de família. ${ }^{1} \mathrm{~A}$ paternidade é um processo que ocorre a partir de práticas de cuidado inseridas na relação entre pais e filhos. Trata-se de uma fase marcada por modificações emocionais, mudanças e conhecimentos que o pai, fundamentalmente, busca para expressar seu papel. ${ }^{2}$ 
O exercício da paternidade requer, além de atitudes proativas de afetividade, conhecimentos para a execução de cuidados básicos com o filho, como a alimentação, higiene, segurança e educação. Deter e aprimorar tais conhecimentos pode permitir aos pais exercer esse papel com autonomia e autoconfiança, o que provavelmente irá contribuir com o desenvolvimento biopsicoemocional dos filhos. Assim, o processo de construção da paternidade demanda adaptações, que geram a necessidade de redes formais (profissionais de saúde e políticas públicas) e informais (família, amigos e colegas de trabalho) para dar suporte no desempenho do papel de pai. ${ }^{3}$

Nessa conjuntura, os profissionais de saúde têm papel relevante. O enfermeiro, por exemplo, pode acompanhar a família em todo seu ciclo vital, desde as ações de promoção à saúde, prevenção, tratamento e recuperação de agravos. Por meio do conhecimento das características individuais e as interações vivenciadas nos diferentes contextos em que o homem/pai se encontra, de modo que consiga estabelecer uma relação de confiança para atender suas necessidades no exercício da paternidade..$^{2-4}$

Assim, essa relação pode se dar a partir de ações educativas grupais, nas consultas do pré-natal, no período puerperal e na puericultura, em visitas domiciliares, nas imunizações, em condições agudas ou crônicas enfrentadas na infância. Todavia, observa-se no cotidiano do trabalho da enfermagem, fragilidades em inserir os pais no atendimento prestado à família, seja em função da acessibilidade organizacional dos serviços de saúde ou dos horários de atendimento.

Nesse sentido, a justificativa deste estudo se encontra à proposição da Política de Atenção Integral à Saúde do Homem (PAISH) que prevê o direito do pai de participar de todo o processo reprodutivo $^{5}$ e a necessidade de dar voz aos pais, a fim de subsidiar as práticas do cuidado no que concerne à assistência às famílias. Dessa forma, questiona-se quais as experiências vivenciadas por homens participantes de um curso de gestante no exercício da 
Experiências narradas por homens no exercício da paternidade: rompendo paradigmas... $\mid 4$

paternidade? Portanto, o objetivo deste estudo foi conhecer as experiências vivenciadas por homens no exercício da paternidade.

\section{Método}

Este é um estudo descritivo-exploratório, com abordagem qualitativa. Os participantes foram homens que acompanharam suas parceiras em curso de gestantes, promovido por docentes e discentes nas disciplinas de Enfermagem à Saúde da Mulher e da Criança do Curso de Graduação em Enfermagem. Cabe mencionar que o referido curso fez parte de um projeto de extensão desenvolvido em um serviço-escola de uma Universidade Comunitária do interior do Rio Grande do Sul, no período de 2013 a 2016.

Para elegibilidade dos participantes, utilizou-se como critério de inclusão: homens que participaram de, no mínimo, quatro dos seis encontros realizados durante o curso de gestantes. E excluiu-se os adolescentes, com registros cadastrais insuficientes (telefone e endereço), o que impediu o acesso. Do total de 21 homens que integraram o Curso de Gestantes, cinco foram excluídos por não terem participado do número mínimo de encontros e um não aceitou participar do estudo. Portanto, participaram da pesquisa 15 homens/pais. Destaca-se que, no período da produção dos dados, os homens vivenciavam a paternidade em diferentes momentos do ciclo vital de seus filhos. A produção de dados ocorreu entre agosto e setembro de 2016, em local e horário determinados pelos participantes, por meio de entrevista narrativa a qual seguiu às cinco fases metodológicas: preparação, iniciação, narração central, perguntas e conclusão do discurso. ${ }^{6}$

$\mathrm{Na}$ fase de preparação, buscou-se estabelecer uma comunicação entre o participante e a pesquisadora. Nesse momento, os homens foram informados sobre o tema da pesquisa, o problema que motivou o estudo, bem como seu objetivo e relevância. Na sequência, foi solicitado o consentimento para participação da investigação por meio da leitura e assinatura do 
Termo de Consentimento Livre e Esclarecido, ficando uma via de posse do participante e outra da pesquisadora.

Posteriormente, partiu-se para a fase de iniciação da narrativa por meio do eixo norteador: Conte-me como tem sido a experiência no exercício da paternidade. Vale mencionar, que durante a narração central dos participantes, atentou-se para não interrompê-los e somente encorajá-los, por meio de uma interação para-linguística.

Conseguinte, a fase de perguntas foi utilizada para esclarecer ou apropriar-se com detalhes da narrativa como, por exemplo: o que aconteceu, então? Poderia dar mais detalhes sobre isso? $\mathrm{Na}$ fase conclusiva, questionou-se sobre a narrativa, a fim de aprofundar a compreensão das perspectivas dos homens e contemplar os objetivos do estudo.

As entrevistas duraram, em média, trinta minutos e foram registradas em um gravador digital e transcritas em Microsoft Office Word. Houve correções de linguagem nas falas, mas sem alterar a essência. A análise dos dados fundamentou-se na proposta temática, a qual se organiza em três fases: pré-análise, exploração do material, tratamento dos resultados, inferência e interpretação. ${ }^{7}$

Na pré-análise, houve a leitura flutuante, seguida da constituição do corpus, de acordo com o objetivo proposto. Para a exploração do material, realizou-se a codificação por meio das palavras ou frases semelhantes nos discursos. ${ }^{7} \mathrm{Na}$ fase de tratamento dos resultados e da interpretação, foi possível agrupar os fragmentos das narrativas em relevo em um quadro teórico, com o intuito de visualizar as informações obtidas com plenitude, bem como abranger as inferências previstas. Desta análise, obtiveram-se os seguintes temas: a paternidade e o cuidado com os filhos; a paternidade versus o impacto pessoal/profissional.

Quanto às questões éticas da pesquisa com seres humanos, salienta-se que foram respeitados todos os preceitos da Resolução do Conselho Nacional de Saúde (CNS) nº 466/12. Dessa forma, o anonimato dos participantes foi garantido por meio da utilização do sistema alfanumérico, utilizando a letra $\mathrm{P}$ (Participante), seguida de números arábicos, 1, 2, até 15. Este 
Experiências narradas por homens no exercício da paternidade: rompendo paradigmas... $\mid 6$

estudo foi aprovado pelo Comitê de Ética e Pesquisa em 20 de junho de 2016, com número no Certificado de Apresentação para Apreciação Ética 57275616.1.0000.5353.

\section{Resultados e discussão}

Os 15 homens tinham idade entre 21 e 41 anos, (9- 60\%) eram católicos, (11- 86,7\%) possuíam plano de saúde privado. Quanto à escolaridade, (1- 6,7\%) possuíam ensino fundamental incompleto, (4-26,7\%) ensino médio completo, (1- 6,7\%) ensino técnico profissionalizante, (1- 6,7\%) graduação completa e (4- 26,7\%) pós-graduação. Em relação ao número de filhos, (1- 6,7\%) possuíam três filhos, (1-6,7\%) dois filhos e (11- 86,7\%) um filho.

A renda dos participantes variou entre menos de um salário mínimo (1- 6,7\%), de um a três salários (5- 33,3\%) e de 10 a 15 salários (9- 60\%). No que se refere à ocupação, declararam-se: professor, bancário, servidor público municipal, servidor público federal, industriário, administrador, motorista e fisioterapeuta; auxiliar de laboratório (2- 13,3\%), eletricistas (213,3\%) e militar (3- 20\%). A partir dessa caracterização, identifica-se que os participantes eram adultos jovens, na sua maioria de classe média, com experiência paterna anterior e não dependiam exclusivamente do Sistema Único de Saúde.

\section{A paternidade e o cuidado com os filhos}

Os homens narraram algumas de suas vivências na paternidade, especialmente no que tange ao cuidado com os filhos em relação à manutenção das necessidades básicas e da educação. Dessa forma, expressaram suas perspectivas acerca da orientação, participação e proteção da dinâmica familiar:

[participo] da função da assistência, da imunização, das campanhas, levei várias vezes. À noite, quando eles [crianças] estão recolhidos eu troco a fralda, levo no banheiro, dou banho, eu que coloco para dormir. (P2) ai vem à responsabilidade de pai, de estar junto, de criar, de educar. (P9) 
eu que assumi o banho, eu que trocava fralda, eu que fazia o suco de laranja do céu com beterraba, nesse caso não ia açúcar, porque a gente aprendeu sobre alimentação, no período certo, depois dos seis meses. (P14)

A partir desses depoimentos, pode-se entender que o cuidado na manutenção da vida ocorre quando os pais preparam a alimentação, realizam higiene corporal, participam de atividades recreativas. Esse cuidado é exercido de forma participativa com a companheira e está presente no cotidiano da vida das crianças.

Esse achado assemelha-se ao estudo que identificou mudanças no modelo patriarcal nos últimos anos, em que o pai era uma figura de autoridade incontestável e não se envolvia na criação e educação dos filhos, porém, com a crescente independência feminina, os papéis começaram a se inverter. ${ }^{8}$ No presente estudo, essa afirmativa ganha destaque, uma vez que todas as companheiras dos participantes estavam inseridas no mercado de trabalho.

Dos 15 homens, três apoiaram a amamentação e a consideraram como fator primordial para o crescimento infantil e vínculo afetivo. Os fragmentos a seguir reforçam que os participantes estão cientes da importância desta prática:

quero e apoio para que seja amamentado no peito, porque é muito importante! A criança fica forte! Pelo menos nos primeiros meses. (P3)

quero que ela amamente, porque o leite materno faz bem para o bebê e para ela. É uma formação de vínculo. (P5)

Durante os depoimentos, os pais se expressaram com entusiasmo e emoção ao se referir sobre esse cuidado. Pôde-se identificar que alguns homens deste estudo apoiam a prática do aleitamento materno, além de reforçarem a relevância da participação neste processo, seja por meio do amparo, incentivo ou proteção, conforme ilustra a percepção do participante:

no curso, falaram da questão da segurança, do vínculo, em estar perto desde o início. Acho que quanto mais presente for, mais vínculo tem com o filho. Também incentivo muito o aleitamento materno. (P7)

Assim, concorda-se que o amamentar é multidimensional e que pode ser vivenciado por todos aqueles, independentemente de ser homem ou mulher, que mantêm vínculo com a mãe e filho, por meio do envolvimento, acolhimento, escuta, compreensão e processo de ajuda. ${ }^{9} \mathrm{~A}$ 
amamentação pode ser vivenciada pelos membros da família e também pelo companheiro, a partir do incentivo e apoio abrangendo, desta forma, o homem e a família no processo de amamentar.

Neste sentido, é importante o amparo do pai para a mãe durante a amamentação, pois as mulheres que se sentem acolhidas pelos parceiros apresentam mais chances de manter a amamentação, mesmo quando se sentem inseguras. Além disso, as mulheres necessitam de alguém que compreenda esse momento e que estabeleça vínculo com ela e com a criança, pois este processo requer um envolvimento físico e emocional. ${ }^{10}$

O fato da temática acerca do aleitamento materno ter sido trabalhada durante o curso de gestantes, mas apenas ter sido mencionada por três dos 15 participantes, conforme foi ilustrado nas falas anteriormente, pode ser um indicativo de que esse tema precisa ser fortalecido entre os pais, uma vez que o seu sucesso ou fracasso também depende do apoio do pai. Além disso, é preciso atentar que, no incentivo ao aleitamento percebe-se uma valorização da figura materna em detrimento da paterna, no entanto, essa última, pode ser decisiva para que a amamentação ocorra efetivamente. ${ }^{10}$

Neste estudo, a participação dos pais na educação dos filhos encontra-se ancorada em princípios éticos e morais, ressaltando-se o papel da família acerca da importância do respeito e do limite para a formação integral dos sujeitos:

[a educação] é de acordo com a visão de Deu em função de todas as coisas que a gente vê e que acontece no mundo [...] a gente vai estreitando os laços, ensinando. Aprende que tem que corrigir, mas como vou corrigir? Corrigir com amor, se o amor estiver presente, ele não causa mágoa, nem dor. Nós como pais, temos que orientar. (P2)

tem que ensinar o respeito, porque está acima da vida. É preciso limite! Não que se vá anular, mas é preciso respeitar a hierarquia que existe. (P15)

Essas falas indicam que os pais se sentem responsáveis pela educação e, imbuídos nessa tarefa, primam pelo diálogo, amor e respeito. A educação representa a transmissão do conhecimento, dos preceitos éticos e morais na sociedade. A conduta humana e o 
posicionamento de cada pessoa em relação aos princípios variam de acordo com o momento de sua vida, não tem caráter definitivo. Assim, estes ensinamentos, primeiramente, são herdados e compartilhados pelos pais, para subsidiar à criança ou o adolescente na formação da sua própria conduta moral. ${ }^{11}$

\section{Paternidade versus o impacto pessoal/profissional}

O momento da gestação e do nascimento do (a) filho (a) foi marcado por fortes emoções. Evidencia-se que os pais estiveram envolvidos de maneira mais intensa após o nascimento, manifestando-se emocionalmente conectados ao bebê.

Antes do nascimento parecia que era um sonho ser pai. Quando eu vi aquele rostinho. Quando me deram parabéns papai! Parece que realmente, agora eu sou pai! (P8)

Eu creio que nós nascemos para sermos geradores de vida, não somente à mulher, preparada com útero e tal, na questão de paradigmas sendo quebrados. (P15)

Percebe-se que a experiência vivenciada gerou emoções positivas, especialmente no período pós-nascimento. Essa condição, frequentemente, é vivenciada de forma intensa e peculiar, dada a instalação de novos processos e aprendizados. Em concordância com outro estudo, a gravidez é um evento repleto de sentimentos na vida do homem e da mulher, no qual deixam de ser apenas filho (a) para se tornarem pai e mãe, ambos vivenciam essa transição com expectativas, anseios e temores. ${ }^{12}$ Assim, a literatura afirma que, ao contrário da maternidade, definida com as mudanças corporais, a paternidade é um conceito relacional que só existe para as pessoas a partir do momento em que o filho nasce, ${ }^{13}$ como expresso por P8.

Essa transformação e alteração no modelo da paternidade implica, na maior parte dos casos, no rompimento do modelo vivenciado, pois os homens estão mais participativos nas questões referentes ao contexto familiar. A função que ele exerce na família, atualmente, está relacionada também com suas características individuais e com o contexto social, onde ocorrem suas interações mais significativas. ${ }^{2}$ Essa afirmativa vem ao encontro do depoimento de P15, quando se refere à quebra de paradigmas. 
Experiências narradas por homens no exercício da paternidade: rompendo paradigmas... $\mid 10$

No que tange ao sentimento de paternidade, os participantes do estudo revelaram que foi uma experiência social e significativa desde o momento em que tomaram conhecimento da gravidez, visto que procuravam participar das consultas de pré-natal, do parto e puerpério. Conforme ilustra-se, a seguir:

essa experiência muda tudo, só quem está passando por aquele momento de ser pai sabe o que significa. (P1)

foi muito bom escutar o coraçãozinho, a gente se sente pai, porque ali dentro da barriga está um serzinho, se formando durante a gravidez. (P11)

Estudos apontam que a paternidade, representa a fase de novas experiências, aprendizados para expressar e lidar com as diferentes emoções. ${ }^{14-15}$ Essa fase pode gerar construções e reconstruções acerca do papel do pai, na medida em que este participa ativamente do processo gravídico-puerperal. ${ }^{15}$

Os homens deste estudo também demonstraram que a vivência da paternidade foi uma experiência que trouxe amadurecimento, além de reflexões e atribuições a respeito da paternidade. O relato a seguir caracteriza essa afirmativa:

eu fui o primeiro a pegar nos braços [o bebê], foi uma emoção que não tem explicação! É uma coisa que não tem preço. Primeiro contato, adaptação, acesso aos meus direitos como pai, como está na constituição, estar presente em todo desenvolvimento da minha filha. (P13)

Essa narrativa chama a atenção na medida em que, além de outras questões, o acesso aos direitos constitucionais impactaram positivamente no exercício da paternidade para esse participante. No Brasil, há legislações que garantem ao homem o direito de exercer ativamente a paternidade, dentre elas cita-se a Lei n 11.108 , de abril de 2005 e a Lei no 13.257 , de março de 2016. Desse modo, cabe também aos profissionais de saúde divulgar e discutir tais legislações, a fim de empoderar homens e mulheres para o exercício da maternidade e paternidade, garantidos legalmente. ${ }^{16}$

Acredita-se que, nas famílias em que o casal trabalha, há um conjunto de exigências que implicam diretamente na articulação dos diferentes papéis que o casal assume (conjugal, 
parental, profissional). Para os homens desse estudo, a paternidade provocou um processo de reorganização no ambiente familiar, o que implicou aos participantes, novas tarefas e responsabilidades:

depois do nascimento é tudo dividido, [...] não existe uma coisa formal, é teu, isso é meu, hoje é tu, hoje não é. Agente, naturalmente, vai se organizando, quem se sente um pouco melhor, vai lá e faz, quando o outro vê que no dia seguinte, tem um dia mais puxado, começa mais cedo, já pega o bebê para o outro poder descansar mais, mas uma coisa natural, não que foi formalizado uma coisa, depende da necessidade nossa. (P6)

a paternidade modificou muita coisa, mas em um sentido positivo, desde cedo, ficou claro que isso o pai ia ter que ser ativo, participativo, parceiro e procurar informação. (P10)

Diante das falas percebe-se que a reorganização familiar ocorreu de forma natural e positiva, com a divisão de tarefas domésticas e a compreensão de que a paternidade exige participação ativa e engajamento nesta relação igualitária construída pelo casal. Estudo reflexivo aponta que a participação dos homens nos cuidados aos filhos e a divisão de tarefas domésticas, tem possibilitado a desintegração de antigos estereótipos paternos e maternos, favorecendo a paternidade participativa. ${ }^{17}$

Assim, a literatura refere que quanto mais o pai ou a mãe estiverem presentes no cotidiano do filho, os laços afetivos e o vínculo entre eles serão efetivos. Casais que dividem as tarefas e participam ativamente da rotina familiar tendem a tornar mais harmoniosa a relação conjugal. ${ }^{10}$

Desse modo, concorda-se com outro estudo que a participação efetiva favorece a formação social e emocional da criança e do pai, e ainda se criam situações de bem-estar, apoio e segurança para todos os envolvidos no processo, inclusive ao estabelecer relações mais igualitárias entre o casal. ${ }^{18}$ Ainda é possível perceber que a paternidade produziu transformações positivas em um dos participantes, como o cuidado de si e a busca por informações para o exercício da paternidade: 
fui para academia para poder acompanhar os outros [filhos]. Tenho que estar em forma para aguentar o pique! Eu me preocupo em estar fisicamente bem, para acompanhar eles. [Procuramos estar] sempre nos atualizando em todas as áreas! Conhecer a tecnologia para acompanhar eles. (P2)

Este depoimento indica que a paternidade pode ser um meio para estimular os homens, tanto para o cuidado com os filhos, como com a própria saúde. Logo, estudo que investigou homens que vivenciaram o pós-nascimento de um filho, corrobora com o processo de redefinição e ressignificação do cuidado, auxiliando no estímulo ao autocuidado. ${ }^{19}$ Ainda, com relação às funções profissionais e o exercício da paternidade, foi observado que os homens assumem o cuidado dos filhos no período da noite, após o horário de trabalho.

Na minha visão de pai, o que eu preciso é ter mais tempo, que o cara tem sua vida rotineira é muito corrido, no sentido de trabalho, compromisso, acaba tendo que tirar tempo de onde não tem para ele [criança], essa que é a verdade. Ela [companheira] já fica o dia todo com ele, porque ela trabalha em casa, chegando na parte da noite, ela dispensa ele para o meu lado, chega essa hora, fico mais com ele. (P10)

mudei meu trabalho, minha função! Eu ficava à noite em casa, então ele ficava comigo, e assim a gente criou laços também por causa dessa aproximação. (P2)

Observa-se, no relato do P10, um esforço para dedicar mais tempo ao filho e, na experiência do $\mathrm{P} 2$, a indicação de que a mudança de função no trabalho propiciou aproximação na relação pai-filho. Esse achado se aproxima de outro estudo em que os pais, ao ocuparem-se com o trabalho, acabaram se distanciando do cuidado e interação com os filhos, porém, relataram desejo de efetivar essa experiência. ${ }^{19}$

No que se refere à paternidade, em um estudo de revisão sistemática sobre paternidade no Brasil, os resultados indicam que, de modo geral, os pais compreendem esse papel como um novo encargo social ainda muito ligado à função de provisão material e moral da família. Porém, vivenciam um processo de transição entre o modelo do pai tradicional e aquele que abrange as dimensões afetiva e de cuidado, ${ }^{19}$ sendo importante ressaltar que a participação do pai favorece a construção do vínculo, estimulando sua responsabilidade na ação de cuidar e estar presente. ${ }^{20}$ 
Desta forma, as experiências vivenciadas pelo pai no contexto familiar e durante as etapas da vida da criança, podem constituir-se como um dado importante para planejamento da assistência de enfermagem, embasada nas necessidades educativas, emocionais e familiares apresentadas pelos pais no exercício da paternidade. Desse modo, cabe ao enfermeiro primar por um cuidado que contribua com o enfrentamento das situações do cotidiano e o estabelecimento de vínculos com a família. ${ }^{2,21}$

\section{Considerações finais}

O estudo propiciou conhecer as experiências vividas por homens-pais no exercício da paternidade. Tais experiências, foram narradas no cuidado com os filhos e no impacto que a paternidade gerou em suas vidas pessoais e profissionais. Os homens-pais vivenciaram o cuidado com os filhos na manutenção da vida de forma igualitária com a companheira, permeados por sentimentos de alegrias e responsabilidades.

Estes achados indicam que os participantes compreendem o exercício da paternidade para além da provisão material, uma vez que participavam nos afazeres domésticos, no cuidado com os filhos e com a companheira. Esse envolvimento favoreceu a afetividade e o bem-estar de toda a família.

Cabe ao profissional de enfermagem inserir e acompanhar a família em todo ciclo vital, por meio de ações de promoção e educação em saúde, compreender o contexto que este pai está inserido, encorajar e estabelecer vínculos. $\mathrm{Na}$ contemporaneidade, os homens participam ativamente no cuidado com o filho, o que facilita a inserção destes no serviço de saúde. Desse modo, torna-se indispensável que o enfermeiro conheça suas características individuais, com ênfase nas experiências pessoais, pois as interações podem facilitar ou dificultar o desempenho de seu papel e, por conseguinte, interferir no exercício da paternidade.

No que tange às limitações do estudo, acredita-se que esteja relacionada às características dos participantes, uma vez que não houve diversidade entre eles em relação ao 
Experiências narradas por homens no exercício da paternidade: rompendo paradigmas... $\mid 14$

perfil socioeconômico. Nessa premissa, sugere-se novas pesquisas com enfoque no exercício da paternidade que explorem outras realidades.

Conclui-se que a investigação contribuiu para a produção de novos conhecimentos com a população masculina acerca da paternidade. Com isso, pode oportunizar a criação de práticas educativas coletivas e individuais com base em necessidades reais, além da possibilidade de transformação no processo de ensino e aprendizagem na área da saúde, por meio da valorização dessa temática no cuidado integral à família.

\section{Referências}

1. Bernardi D. Paternidade e cuidado: "novos conceitos", velhos discursos. Psicol Rev [Internet]. 2017 [acesso em 2018 jun 24];(26)1:59-80. Disponível em: https://revistas.pucsp.br/index.php/psicorevista/article/view/28743/23329.

2. Silva BT, Silva MRS, Bueno MEN. Eventos intra e extrafamiliar significativos no processo de construção da paternidade. Esc Anna Nery Rev Enferm [Internet]. 2014 out-dez [acesso em 2016 out 05];18(4):710-5. Disponível em: http://www.scielo.br/pdf/ean/v18n4/1414-8145-ean-18-04-0710.pdf. doi: 10.5935/1414-8145.20140101.

3. Moraes CJA, Granato TMM. Tornando-se pai: uma revisão integrativa da literatura sobre a transição para a paternidade. Psicol Estud [Internet]. 2016 out-dez [acesso em 2018 jun 23];21(4):557-67. Disponível em: http://www.periodicos.uem.br/ojs/index.php/PsicolEstud/

article/view/29871/pdf. doi:10.4025/psicolestud.v21i4.29871.

4. Santos FPA, Acioli S, Rodrigues VP, Machado JC, Souza MS, Couto TA. Práticas de cuidado da enfermeira na Estratégia Saúde da Família. Rev Bras Enferm [Internet]. 2016 nov-dez [acesso em 2017 jan 04];69(6):1060-7. Disponível em: http://www.scielo.br/pdf/reben/v69n6/en_0034-7167-reben-69-06-1124.pdf. doi: 10.1590/0034-7167-2016-0273.

5. Brasil. Ministério da Saúde. Política Nacional de Atenção Integral à Saúde do Homem: princípios e diretrizes. Brasília (DF): Ministério da Saúde; 2009.

6. Muylaert CJ, Sarubbi Júnior V, Gallo PR, Neto MLR, Reis AOA. Entrevistas narrativas: um importante recurso em pesquisa qualitativa. Rev Esc Enferm USP [Internet]. 2014 [acesso em 2017 jan 04];48(N Esp2):193-9. Disponível em: https://www.revistas.usp.br/reeusp/ article/view/103125. doi:10.1590/S0080623420140000800027.

7. Minayo, MCS. O desafio do conhecimento. 14르 ed. São Paulo: Hucitec; 2014. 
8. Vieira ML, Bossardi CN, Gomes LB, Bolze SDA, Crepaldi MA, Piccinini CA. Paternidade no Brasil: revisão sistemática de artigos empíricos. Arq Bras Psicol [Internet]. 2014 out [acesso em 2016 nov 13];66(2):36-52. Disponível em: http://pepsic.bvsalud.org/pdf/arbp/v66n2/04.pdf.

9. Resende TC, Dias EP, Cunha CMC, Mendonça GS, Ribeiro Júnior AL, Santos LRL, et al. Participação paterna no período da amamentação: importância e contribuição. Biosci J [Internet]. 2014 maio-jun [acesso em 2016 nov 14];30(3):925-32. Disponível em: http://www.seer.ufu.br/index.php/biosciencejournal/article/view/23591.

10. Jeneral RBR, Bellini LA, Duarte CR, Duarte MF. Aleitamento materno: uma reflexão sobre o papel do pai. Rev Fac Cienc Med Sorocaba [Internet]. 2015 [acesso em $2016 \mathrm{dez}$ 01];17(3):140-7. Disponível em: https://revistas.pucsp.br/index.php/RFCMS/article/view/21445.

11. Moura GC, Lins DRT, Santos NF, Santos RCL. Avaliação inter e transgeracional da família. Cad Grad Ciênc Hum Soc Unit [Internet]. 2016 abr [acesso em 2016 out 13];3(2):61-72. Disponível em: https://periodicos.set.edu.br/index.php/fitshumanas/article/view/2305.

12. Srivastava A, Avan BI, Rajbangshi P, Bhattacharyya S. Determinants of women's satisfaction with maternal health care: a review of literature from developing countries. BMC Pregnancy Childbirth [Internet]. 2015 [acesso em 2016 nov 02];15:97. Disponível em: https://bmcpregnancychildbirth.biomedcentral.com/articles/10.1186/s12884-015-0525-0. doi: 10.1186/s12884-015-0525-0.

13. Cúnico SD, Arpini DM. A família em mudanças: desafios para a paternidade contemporânea. Pensando Fam [Internet]. 2013 mar [acesso em 2016 dez 02];17(1):28-40. Disponível em: http://pepsic.bvsalud.org/pdf/penf/v17n1/v17n1a04.pdf.

14. Corrêa ACL, Meincke SMK, Schwartz E, Oliveira AMN, Soares MC, Jardim VMR. Percepções de homens sobre a vivência da paternidade na adolescência: uma perspectiva bioecológica. Rev Gaúch Enferm [Internet]. 2016 mar [acesso em 2016 out 10];7(1):e54692. Disponível em: http://www.seer.ufrgs.br/index.php/RevistaGauchadeEnfermagem/article/

view/54692/37069. doi: 10.1590/1983-1447.2016.01.54692.

15. Ferreira IS, Fernandes AFC, Lô KKR, Melo TP, Gomes AMF, Andrade IS. Percepções de gestantes acerca da atuação dos parceiros nas consultas de pré-natal. Rev RENE [Internet]. 2016 maio-jun [acesso em 2016 nov 07];17(3):318-23. Disponível em: http://www.revenf.bvs.br/pdf/rene/v17n3/1517-3852-rene-173-0318.pdf. doi: 10.15253/2175-6783.2016000300003.

16. Frutuoso LD, Brüggemann OM. Conhecimento sobre a Lei 11.108/2005 e a experiência dos acompanhantes junto à mulher no centro obstétrico. Texto \& Contexto Enferm [Internet]. 2013 [acesso em 2016 nov 07];22(4):909-17. Disponível em: http://www.scielo.br/pdf/tce/v22n4/06.pdf. doi: 10.1590/S0104-07072013000400006. 
Experiências narradas por homens no exercício da paternidade: rompendo paradigmas... | 16

17. Gradvohl SMO, Osis MJD, Makuch MY. Maternidade e formas de maternagem desde a Idade Média à atualidade. Pensando Fam [Internet]. 2014 jun [acesso em 2018 jun 20];(18)1:06-13. Disponível em: http://pepsic.bvsalud.org/pdf/penf/v18n1/v18n1a06.pdf.

18. Teixeira RC, Mandú ENT, Corrêa ACP, Marcon SS. Vivências e necessidades de saúde de homens no período pós-nascimento de um filho. Rev Bras Enferm [Internet]. 2014 set-out [acesso em 2016 out 28];67(5):780-7. Disponível em: http://www.scielo.br/pdf/reben/v67n5/0034-7167-reben-67-05-0780.pdf. doi: 10.1590/0034-7167.2014670516.

19. Vieira ML, Bossardi CN, Gomes LB, Bolze SDA, Crepaldi MA, Piccinini, C. Paternidade no Brasil: revisão sistemática de artigos empíricos. Arq Bras Psicol [Internet]. 2014 [acesso em 2016 dez 10];66(2):3652. Disponível em: http://seer.psicologia.ufrj.br/index.php/abp/article/view/854/859.

20. Strapasson MR, Lima BSS, Ferreira GE, Oliveira GC, Bonilha ALL, Paz PO. Percepção do pai acerca da paternidade no alojamento conjunto. Rev Enferm UFSM [Internet]. 2017 jan-fev [acesso em 2017 mar 16];7(1):80-9. Disponível em: https://periodicos.ufsm.br/reufsm/article/view/22295/pdf. doi: $10.5902 / 2179769222295$.

21. Prigol AP, Baruffi LM. O papel do enfermeiro no cuidado à puérpera. Rev Enferm UFSM [Internet]. 2017 jan-fev [acesso em 2017 mar 16];7(1):1-8. Disponível em: https://periodicos.ufsm.br/reufsm/article/view/22286/pdf. doi: 10.5902/2179769222286.

\title{
Autor correspondente:
}

Glaucia Resta Dal-Rosso

E-mail: glauciaresta@gmail.com

Endereço: Rua Duque de Caxias, 185, Centro. Santiago/RS.

CEP: $97700-000$

\section{Contribuições de Autoria}

\author{
1 - Glaucia Resta Dal-Rosso \\ Concepção do projeto, análise dos dados e redação do artigo.
}

\section{2 - Silvana de Oliveira Silva}

concepção do projeto, análise dos dados e redação do artigo.

\section{3 - Greice Machado Pieszak}

auxílio na revisão crítica do conteúdo intelectual e aprovação final da versão final a ser publicada.

\section{4 - Sandra Beatris Diniz Ebling}

auxílio na revisão crítica do conteúdo intelectual e aprovação final da versão final a ser publicada. 


\section{Como citar este artigo}

Dal-Rosso GR, Silva SO, Pieszak GM, Ebling SBD, Silveira VN. Experiências narradas por homens no exercício da paternidade: rompendo paradigmas. Rev. Enferm. UFSM. 2019 [Acesso em: 2019 jun 15]; vol ex:1-17. DOI:https://doi.org/10.5902/2179769228653 